\title{
Vorwort und Dank
}

Das Bedürfnis, den täglichen Sorgen und der Unruhe im Jahr 2020 Konzentration und Ablenkung gleichermaßen entgegenzusetzen, führte dazu, dass ich die Unterlagen der Antrittsvorlesung wieder aufnahm, welche ich im Sommer 2013 an der Heidelberger Ruperto Carola gehalten hatte. Unter dem Titel ,guldine linge. Ästhetische Transformationen von Wissen in Gottfrieds Tristan" bezweckte ich seinerzeit programmatisch Fragestellungen meiner künftigen Forschungen zu exponieren. Gottfrieds Tristan war dabei eine besondere Rolle zugedacht. Es kam dann naturgemäß alles ganz anders, was auch mit dem enormen Anregungspotential meiner neuen Umgebung zu tun hatte. Die damaligen Ausführungen galten dem Gold in Gottfrieds Roman und seiner metaphorischen Übertragung auf Sprache und Dichtung. Der Versuch, die Poetik des Textes aus seiner multiplen Kontextbezüglichkeit nachzuzeichnen, schien mir auch nach der langen Zeit noch tragfähig. Diese Überlegungen lege ich nun ausgebaut und um neue Aspekte ergänzt als fünf Essays vor. Von einer monographischen Abhandlung mit dem Anspruch, das Romanfragment insgesamt zu würdigen, habe ich abgesehen, weil hier angesichts der dichten und verdienstreichen Tristan-Forschung zu vielen Aspekten des Textes Redundanz drohte.

Die Frage, ob es wirklich noch eines weiteren Tristan-Buches bedarf, beunruhigte mich. Ich mache die freundlichen Ermunterungen zur Veröffentlichung und auch die kritischen Diskussionen meiner Überlegungen für das Vorliegen des Bändchens verantwortlich, welche mich von Seiten alter und neuer Freundinnen und Freunde erreichten. Sophie Knapp hat zuerst alle Essays kritisch ausgewertet und somit die Voraussetzung dafür geschaffen, dass sie inhaltlich und sprachlich weiteren anspruchsvollen Leserinnen und Lesern zumutbar waren. Für die Lektüre einzelner Teile des Buches und die kritische Auseinandersetzung mit ihnen danke ich herzlich Stefan Seeber, Isabella Managò, Romedio Schmitz-Esser, Herfried Vögel, Alexander Rudolph, Jonas Grethlein, Regina Toepfer und Susanne Reichlin. Zu danken habe ich auch Ludger Lieb und den Teilnehmenden unseres gemeinsamen Forschungskolloquiums für die Diskussion des Minnegrotten-Essays. Carola Kasimir danke ich für unermüdliches Korrekturlesen und Literaturbesorgungen, Sophie Knapp und Martin Schneider kamen bei den Endkorrekturen zu Hilfe. Dem Reichert Verlag danke ich für die Aufnahme des Manuskripts ins Verlagsprogramm, Anna Sara Lahr habe ich für das fachkundige und gründliche Lektorat sowie für den Satz zu danken.

Da ein Buchprojekt - und sei es auch klein - sich immer wie ein neues Mitglied im Haushalt anfühlt und aufführt, welches eigene Ansprüche stellt an Aufmerksamkeit und Pflege, eigensinnig auf seinen vorgeblichen Rechten beharrt und sich hin und wieder auch unhöflich benimmt, habe ich meinen beiden Kindern und meiner Frau sehr zu danken, die der Sache mit verlässlicher Nachsicht und Großmut, manchmal sogar mit Neugier begegnet sind. 